\title{
Endüstri Yapısı Temeline Yönelik Vaka Analizi
}

\author{
$1 *$ Sedat Sert, ${ }^{2}$ Aşkın Özocak, ${ }^{3}$ Ertan Bol \\ Sakarya Üniversitesi, Mühendislik Fakültesi, İnşaat Mühendisliği Bölümü
}

\section{$\ddot{O} \mathbf{z}$}

Bu makalede, Sakarya / Türkiye'de geoteknik açıdan problemli zeminler üzerinde yapılması düşünülen bir endüstri yapısının inşaası sonrasında karşılaşılabilecek olası sorunların jet-grout/kazık kullanılarak giderilmesine yönelik bir vaka analizi sunulmaktadır. Tek katlı fabrika yapısı yaklaşık $8200 \mathrm{~m}^{2}$ 'lik bir alan üzerinde inşa edilecektir. Toplam uzunluğu $220 \mathrm{~m}$ olan 11 sondaj ve bunun yanında 5 tane de koni penetrasyon deneyi sonucunun değerlendirilmesiyle alanda yüzeye yakın zeminlerin yumuşak yüksek plastisiteli killerden oluştuğu, daha sonra 8-10 m'lere kadar sıvılaşabilir kumlu ve siltli zeminlerin bulunduğu anlaşılmıştır. Alanda orta sıkı / sıkı kumların bazı yerlerde 7.50 m'lerde başladığı ve $12 \mathrm{~m}$ derinliğe kadar devam ettiği de tespit edilmiştir. Yer altı su seviyesinin $1.70 \mathrm{~m}-2.00 \mathrm{~m}$ civarında bulunduğu ortamda olası sıvılaşmanın neden olabileceği oturmaların önüne geçmek için analizler sonrasında $11 \mathrm{~m}$ derinliğe kadar iyileştirme yapılması gerektiği ortaya çıkmıştır. Zemin iyileştirmesine alternatif olarak şerit temeller altında $60 \mathrm{~cm}$ çaplı, $10 \mathrm{~m}$ uzunluğundaki kazıkların kullanılması da sıvılaşma sonrası oturmaları azaltmak için yeterli olacaktır. Sıvılaşma problemine ek olarak alanda 1999 depremleri sonrasında ortaya çıkan morfolojik bozukluğun mevcut olması yeni binanın yer seçimini önemli hale getirmiştir. Buna yönelik olarak alanda morfolojik düzensizliğe dik yönde uzunluğu $24 \mathrm{~m}$, genişliği $1.50 \mathrm{~m}$ ve derinliği $2 \mathrm{~m}$ olan bir hendek çalışması yürütülmüştür. Burada morfolojik düzensizliğin durumu tespit edilerek yapının yeri morfolojik düzensizlikten yeteri kadar uzakta seçilmiştir. Böylece gerekli iyileştirme ile yapının güvenli bir şekilde hizmet verebileceği düşünülmektedir.

Anahtar Kelimeler: Endüstri yapısı temeli, sıvılaşma, jeomorfolojik düzensizlik, zemin iyileştirmesi, jet-grout

\section{A Case Study for an Industrial Building Foundation}

\begin{abstract}
This article is about the solution of geotechnical problems by using piled foundation and jet grouting technique prior to the construction of an industrial building in Sakarya, Turkey. A one-story factory building was planned to be built and the area covers approximately $8200 \mathrm{~m}^{2}$. After the evaluation of 11 borings (total depth of $220 \mathrm{~m}$ ) and 5 soundings, it was understood that top layers of the study area consist of soft high plasticity clays while liquefiable sandy and silty soils, up to $8-10 \mathrm{~m}$, were encountered. Medium or dense sand layers were encountered between the depth of $7.50 \mathrm{~m}$ and $12.0 \mathrm{~m}$. Ground water level is at a depth between $1.70 \mathrm{~m}$ to $2.00 \mathrm{~m}$ below the surface. Soil investigations show that soil improvement was necessary up to $11 \mathrm{~m}$ to prevent settlement problems induced by liquefaction. Another option is to use piles under strip foundations. Piles having radius of $60 \mathrm{~cm}$ and length of $10 \mathrm{~m}$ were calculated to be enough to decrease post-earthquake settlements to acceptable limits. In addition to this problem, because a morphological disorder was observed in the near vicinity of the area just after the 1999 earthquakes, the place of the intended building becomes very important. An exploratory trench, which has a length of $24 \mathrm{~m}$, depth of $2 \mathrm{~m}$ and width of $1.50 \mathrm{~m}$, was oriented perpendicular to the disorder to identify the properties of the geomorphological disorder. The difference along the trench was determined and the building was decided to be built far enough to the disorder. After detailed investigation of soils by borings and soundings and observation of the geomorphological disorder, the building was thought to be built safely by determining the foundation place far enough from the disorder and on treated ground improved with high modulus columns.
\end{abstract}

Keywords: Industrial building foundation, liquefaction, geomorphological disorder, soil improvement, jetgrouting

\section{GİRIŞ}

Bu çalışmada Sakarya / Türkiye'de yapılması düşünülen bir fabrika yapısının üzerinde oturacağı zeminlerin geoteknik açıdan değerlendirilmesi yapılmaktadır. Ayrıca, 1999 depreminde oluşmuş ve çalışma alanı sınırları içinden de geçen morfolojik düzensizlik (çöküntü) hattının yapılması 
düşünülen fabrika binasına risk teşkil edip etmeyeceğinin belirlenmesi ve gerekirse yapılacak olan zemin iyileştirme tekniklerinin de ortaya konması amaçlanmaktadır. Toplam 328873.52 $\mathrm{m}^{2}$ 'lik alana yayılan fabrika arsasında yeni binanın $8200 \mathrm{~m}^{2}$ 'lik bölüme inşası öngörülmekte olup, imalat $40.00 \mathrm{~m} \times 205.00 \mathrm{~m}$ boyutlarında çelik yapı olarak planlanmaktadır.

Çalışma alanı Mithatpaşa mevkiinde Çark deresi etki alanında yer almaktadır (Şekil 1). Ayrıca çalışma alanı Maltepe mahallesinde yüzeylenen Üst Kretase yaşlı Akveren Formasyonunun tepelik kısımlarının eteklerinde yer almaktadır.

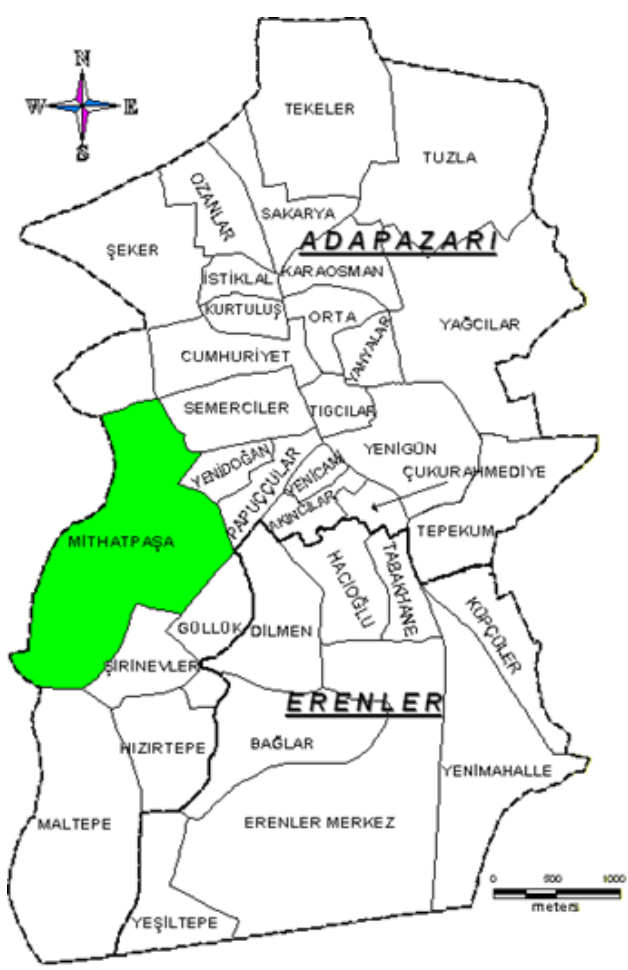

Şekil 1. Çalışma alanı yer bulduru haritası

\section{ARAZI VE \\ ÇALIŞMALARI \\ LABORATUVAR}

Arazide Şekil 2'de belirtilen noktalarda 2016 Ocak - Mart aylarında toplam uzunluğu 220 m olan 11 adet dönel sondaj yapılmıştır. Sondajlardan elde edilen örselenmiş ve örselenmemiş numuneler üzerinde fiziksel ve mekanik özelliklerin tayinine yönelik olarak elek analizi, kıvam limitleri, üç eksenli hücre kesme deneyleri gibi laboratuvar deneyleri yapılmış olup sonuçlar Tablo 1'de özetlenmiştir. Sonuçların derinliğe göre sıralandığ Tablo 1 incelendiğinde şu sonuç çıkartılabilmektedir: Üst 4.50 metrede yüksek plastisitesi killer kesilmekte, bunun altında 7.50 metreye kadar orta plastisiteli killer silt ara katk1lı olarak yataklanmaktadır. Tüm sondaj kuyularında takriben $7.50 \mathrm{~m}$ ve sonrasında yüksek darbe sayıları veren s1k1 kum tabakalarının varlığı görülmektedir (Şekil 3). Sıkı kumlar yaklaşık 12.00 metreye kadar devam etmekte, bu seviyenin altında ise yer yer yüksek plastisiteli killerin ara katk1lı olarak bulunduğu siltli tabakalar bulunmaktadır. Çalışma alanında yeraltı su seviyesine 2016 Ocak-Mart aylarında $1.70 \mathrm{~m}$ ile $2.00 \mathrm{~m}$ seviyelerinde rastlanıldığ 1 rapor edilmiştir.

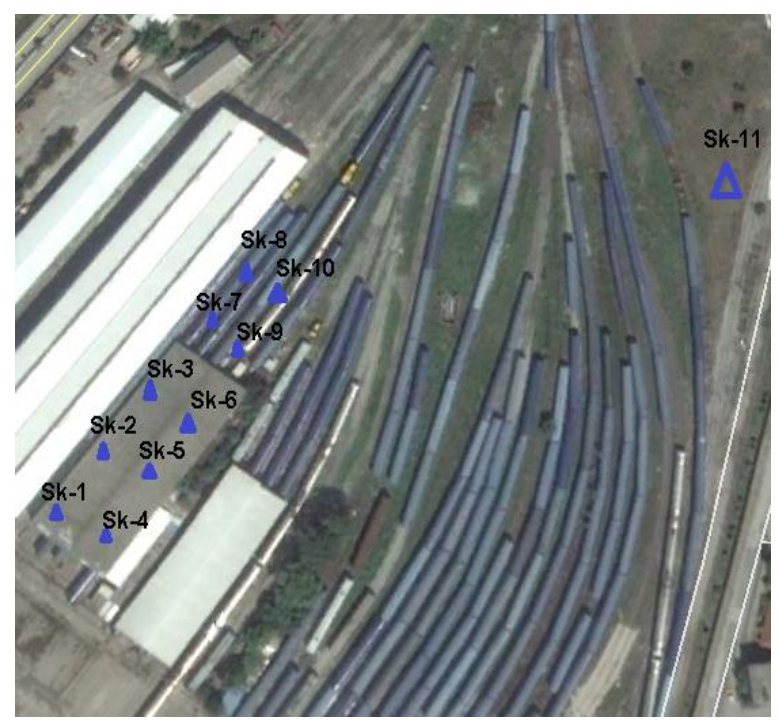

Şekil 2. Sondaj yerleri

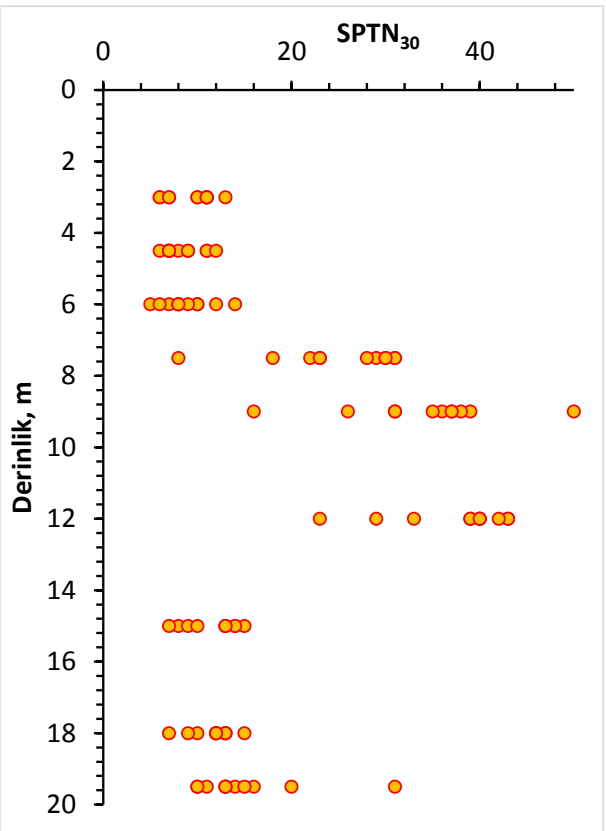

Şekil 3. Sondaj kuyularında SPTN 30 'un derinlikle değişimi 
Tablo 1. Zemin özelliklerinin derinlikle değişimi

\begin{tabular}{|c|c|c|c|c|c|c|c|c|c|c|c|c|c|}
\hline SK & $\mathrm{z}(\mathrm{m})$ & Renk & $\mathrm{W}_{\mathrm{n}}$ & $\mathrm{w}_{\mathrm{L}}$ & $\mathrm{w}_{\mathrm{P}}$ & $\mathrm{I}_{\mathrm{P}}$ & $\mathrm{I}_{\mathrm{L}}$ & $\%$ İnce & $\%$ Çakıl & $\% \mathrm{Kum}$ & Sinif & $\% \mathrm{Kil}$ & SPTN \\
\hline 1 & 3.00 & $\mathrm{~K}$ & 47 & 83 & 27 & 56 & 0.36 & 87 & 0 & 13 & $\mathrm{CH}$ & & 6 \\
\hline 2 & 3.00 & K & 40 & 80 & 30 & 50 & 0.20 & 100 & 0 & 0 & $\mathrm{CH}$ & & 11 \\
\hline 3 & 3.00 & K & 37 & 82 & 29 & 53 & 0.15 & 94 & 0 & 6 & $\mathrm{CH}$ & & 11 \\
\hline 4 & 3.00 & K & 38 & 81 & 29 & 52 & 0.18 & 93 & 0 & 7 & $\mathrm{CH}$ & & 10 \\
\hline 5 & 3.00 & K & 36 & 86 & 31 & 56 & 0.09 & 93 & 0 & 7 & $\mathrm{CH}$ & & 13 \\
\hline 6 & 3.00 & K & 41 & 89 & 31 & 58 & 0.18 & 99 & 0 & 1 & $\mathrm{CH}$ & & 6 \\
\hline 7 & 3.00 & $\mathrm{aKY}$ & 38 & 74 & 26 & 48 & 0.26 & 99 & 0 & 1 & $\mathrm{CH}$ & & 0 \\
\hline 8 & 3.00 & K & 40 & 74 & 29 & 45 & 0.25 & 96 & 0 & 4 & $\mathrm{CH}$ & & 7 \\
\hline 9 & 3.00 & K & 36 & 79 & 30 & 49 & 0.13 & 97 & 0 & 3 & $\mathrm{CH}$ & & 7 \\
\hline 10 & 3.00 & K & 38 & 84 & 30 & 54 & 0.14 & 99 & 0 & 1 & $\mathrm{CH}$ & & 11 \\
\hline 11 & 3.00 & YK & 35 & 61 & 22 & 39 & 0.35 & 86 & 0 & 14 & $\mathrm{CH}$ & & 11 \\
\hline 1 & 4.50 & K & 39 & 79 & 27 & 52 & 0.22 & 94 & 0 & 6 & $\mathrm{CH}$ & & 7 \\
\hline 2 & 4.50 & $\mathrm{~K}$ & 37 & 56 & 25 & 31 & 0.36 & 93 & 0 & 7 & $\mathrm{CH}$ & & 8 \\
\hline 3 & 4.50 & $\mathrm{~K}$ & 36 & 57 & 24 & 33 & 0.36 & 94 & 0 & 6 & $\mathrm{CH}$ & & 6 \\
\hline 4 & 4.50 & KY & 40 & 79 & 28 & 51 & 0.24 & 99 & 0 & 1 & $\mathrm{CH}$ & & 11 \\
\hline 5 & 4.50 & KY & 39 & 76 & 27 & 48 & 0.24 & 91 & 0 & 9 & $\mathrm{CH}$ & & 7 \\
\hline 6 & 4.50 & K & 35 & 80 & 27 & 53 & 0.16 & 86 & 0 & 14 & $\mathrm{CH}$ & & 9 \\
\hline 7 & 4.50 & $\mathrm{aK}$ & 39 & 76 & 25 & 52 & 0.27 & 99 & 0 & 1 & $\mathrm{CH}$ & & 9 \\
\hline 8 & 4.50 & K & 41 & 78 & 27 & 51 & 0.29 & 96 & 0 & 4 & $\mathrm{CH}$ & & 7 \\
\hline 9 & 4.50 & K & 39 & 78 & 29 & 49 & 0.21 & 96 & 0 & 4 & $\mathrm{CH}$ & & 7 \\
\hline 10 & 4.50 & K & 41 & 83 & 28 & 55 & 0.25 & 98 & 0 & 2 & $\mathrm{CH}$ & & 11 \\
\hline 11 & 4.50 & YG & 41 & 84 & 26 & 58 & 0.26 & 100 & 0 & 0 & $\mathrm{CH}$ & & 12 \\
\hline 1 & 6.00 & $\mathrm{~K}$ & 39 & 38 & 25 & 13 & 1.13 & 81 & 0 & 19 & CI & & 14 \\
\hline 2 & 6.00 & K & 38 & 43 & 21 & 22 & 0.75 & 90 & 0 & 10 & CI & & 10 \\
\hline 3 & 6.00 & K & 37 & 40 & 25 & 5 & 0.84 & 89 & 0 & 11 & CI & & 7 \\
\hline 4 & 6.00 & KY & 36 & 44 & 25 & 20 & 0.57 & 87 & 0 & 13 & CI & & 8 \\
\hline 5 & 6.00 & $\mathrm{~K}$ & 33 & 46 & 20 & 26 & 0.51 & 78 & 0 & 22 & CI & & 12 \\
\hline 6 & 6.00 & K & 33 & 42 & 21 & 21 & 0.58 & 78 & 0 & 22 & CI & & 5 \\
\hline 7 & 6.00 & $\mathrm{YaK}$ & 35 & NP & NP & NP & - & 73 & 0 & 27 & ML & 8 & 6 \\
\hline 8 & 6.00 & YG & 27 & NP & NP & NP & - & 59 & 0 & 41 & ML & 8 & 10 \\
\hline 9 & 6.00 & $\mathrm{~K}$ & 37 & 48 & 23 & 25 & 0.56 & 91 & 0 & 9 & CI & & 8 \\
\hline 10 & 6.00 & KY & 34 & 33 & 24 & 9 & 1.00 & 76 & 0 & 24 & ML & & 9 \\
\hline 11 & 6.00 & YG & 40 & 67 & 30 & 36 & 0.26 & 97 & 0 & 3 & $\mathrm{CH}$ & & 8 \\
\hline 1 & 7.50 & $\mathrm{G}$ & 18 & NP & NP & NP & - & 19 & 5 & 76 & SM & & 31 \\
\hline 2 & 7.50 & G & 25 & NP & NP & NP & - & 13 & 2 & 85 & SM & & 23 \\
\hline 3 & 7.50 & G & 25 & NP & NP & NP & - & 13 & 0 & 87 & SM & & 22 \\
\hline 4 & 7.50 & G & 23 & NP & NP & NP & - & 11 & 0 & 89 & SP-SM & & 29 \\
\hline 5 & 7.50 & G & 21 & NP & NP & NP & - & 13 & 1 & 86 & SM & & 30 \\
\hline 6 & 7.50 & Y & 23 & NP & NP & NP & - & 48 & 0 & 52 & SM & & 18 \\
\hline 7 & 7.50 & Y & 22 & NP & NP & NP & - & 11 & 1 & 88 & SP-SM & & 23 \\
\hline 8 & 7.50 & G & 17 & NP & NP & NP & - & 15 & 4 & 81 & SM & & 31 \\
\hline 9 & 7.50 & G & 25 & NP & NP & NP & - & 12 & 1 & 87 & SM & & 30 \\
\hline 10 & 7.50 & G & 26 & NP & NP & NP & - & 14 & 1 & 85 & SM & & 28 \\
\hline 11 & 7.50 & YG & 31 & 37 & 25 & 12 & 0.50 & 77 & 0 & 23 & MI & & 8 \\
\hline 1 & 9.00 & $\mathrm{G}$ & 18 & NP & NP & NP & - & 22 & 2 & 76 & SM & & 39 \\
\hline 2 & 9.00 & G & 25 & NP & NP & NP & - & 13 & 1 & 86 & SM & & 38 \\
\hline 3 & 9.00 & G & 24 & NP & NP & NP & - & 14 & 2 & 84 & SM & & $\mathrm{R}$ \\
\hline 4 & 9.00 & G & 23 & NP & NP & NP & - & 13 & 1 & 86 & SM & & 37 \\
\hline 5 & 9.00 & G & 22 & NP & NP & NP & - & 12 & 1 & 87 & SM & & 31 \\
\hline 6 & 9.00 & YG & 19 & 26 & 19 & 7 & 0.06 & 56 & 0 & 44 & CL & & 26 \\
\hline 7 & 9.00 & Y & 22 & NP & NP & NP & - & 10 & 1 & 89 & SP-SM & & 31 \\
\hline 8 & 9.00 & G & 17 & NP & NP & NP & - & 12 & 5 & 83 & SM & & 36 \\
\hline 9 & 9.00 & G & 24 & NP & NP & NP & - & 13 & 1 & 86 & SM & & 35 \\
\hline 10 & 9.00 & G & 23 & NP & NP & NP & - & 16 & 1 & 83 & SM & & 37 \\
\hline 11 & 9.00 & KY & 39 & 88 & 32 & 56 & 0.12 & 99 & 0 & 1 & $\mathrm{CH}$ & & 16 \\
\hline 1 & 12.00 & $\mathrm{G}$ & 17 & NP & NP & NP & - & 16 & 7 & 77 & SM & & 23 \\
\hline 2 & 12.00 & GY & 25 & NP & NP & NP & - & 13 & 1 & 86 & SM & & 40 \\
\hline
\end{tabular}


Tablo 1. Zemin özelliklerinin derinlikle değişimi (devam)

\begin{tabular}{|c|c|c|c|c|c|c|c|c|c|c|c|c|c|}
\hline SK & $\mathrm{z}(\mathrm{m})$ & Renk & $\mathrm{W}_{\mathrm{n}}$ & $\mathrm{W}_{\mathrm{L}}$ & $\mathrm{WP}_{\mathrm{P}}$ & $\mathrm{I}_{\mathrm{P}}$ & $\mathrm{I}_{\mathrm{L}}$ & $\%$ İnce & \% Çakıl & $\%$ Kum & Sinif & $\% \mathrm{Kil}$ & SPTN \\
\hline 3 & 12.00 & $\mathrm{G}$ & 25 & NP & NP & NP & - & 12 & 2 & 86 & SP-SM & & 39 \\
\hline 4 & 12.00 & $\mathrm{G}$ & 23 & NP & NP & NP & - & 11 & 2 & 87 & SP-SM & & 43 \\
\hline 5 & 12.00 & $\mathrm{G}$ & 23 & NP & NP & NP & - & 12 & 3 & 85 & SM & & 43 \\
\hline 6 & 12.00 & $\mathrm{G}$ & 21 & NP & NP & NP & - & 25 & 4 & 71 & SM & & 33 \\
\hline 7 & 12.00 & $\mathrm{Y}$ & 22 & NP & NP & NP & - & 11 & 1 & 88 & SP-SM & & 42 \\
\hline 8 & 12.00 & $\mathrm{G}$ & 22 & NP & NP & NP & - & 12 & 8 & 80 & SM & & 40 \\
\hline 9 & 12.00 & $\mathrm{G}$ & 23 & NP & NP & NP & - & 13 & 3 & 84 & SM & & 39 \\
\hline 10 & 12.00 & $\mathrm{G}$ & 21 & NP & NP & NP & - & 19 & 3 & 78 & SM & & 40 \\
\hline 11 & 12.00 & $\mathrm{YkG}$ & 25 & NP & NP & NP & - & 52 & 0 & 48 & ML & & 29 \\
\hline 1 & 15.00 & YG & 37 & 39 & 28 & 11 & 0.73 & 9 & 0 & 10 & MI & & 14 \\
\hline 2 & 15.00 & YG & 28 & 24 & NP & NP & - & 58 & 0 & 42 & ML & 7 & 15 \\
\hline 3 & 15.00 & $\mathrm{Y}$ & 38 & 36 & 29 & 7 & 1.35 & 92 & 0 & 8 & MI & & 13 \\
\hline 4 & 15.00 & GY & 28 & NP & NP & NP & - & 64 & 0 & 36 & ML & & 14 \\
\hline 6 & 15.00 & YG & 39 & 44 & 28 & 16 & 0.66 & 96 & 0 & 4 & MI & & 8 \\
\hline 7 & 15.00 & $\mathrm{YaK}$ & 33 & 36 & 19 & 17 & 0.84 & 69 & 1 & 30 & CI & & 9 \\
\hline 8 & 15.00 & YG & 33 & 32 & NP & NP & - & 79 & 0 & 21 & ML & 10 & 13 \\
\hline 9 & 15.00 & YG & 39 & 36 & NP & NP & - & 93 & 0 & 7 & ML & & 10 \\
\hline 10 & 15.00 & YG & 35 & 39 & 22 & 17 & 0.74 & 73 & 0 & 27 & CI & & 13 \\
\hline 11 & 15.00 & YG & 36 & 35 & NP & NP & - & 98 & 0 & 2 & ML & 10 & 7 \\
\hline 1 & 18.00 & YG & 38 & 37 & NP & NP & - & 94 & 0 & 6 & ML & & 13 \\
\hline 2 & 18.00 & YG & 35 & 34 & NP & NP & - & 88 & 0 & 12 & ML & & 13 \\
\hline 3 & 18.00 & YG & 30 & NP & NP & NP & - & 63 & 1 & 36 & ML & & 12 \\
\hline 4 & 18.00 & YG & 30 & 42 & 26 & 16 & 0.24 & 86 & 0 & 14 & CI & & 13 \\
\hline 5 & 18.00 & $\mathrm{Y}$ & 32 & 44 & 20 & 24 & 0.51 & 71 & 0 & 29 & CI & & 10 \\
\hline 6 & 18.00 & YG & 43 & 5 & 24 & 27 & 0.74 & 95 & 0 & 5 & $\mathrm{CH}$ & & 7 \\
\hline 7 & 18.00 & $\mathrm{aY}$ & 35 & 36 & 19 & 17 & 0.91 & 75 & 0 & 25 & CI & & 9 \\
\hline 8 & 18.00 & YG & 34 & 33 & NP & NP & - & 78 & 0 & 22 & $\mathrm{ML}$ & 9 & 12 \\
\hline 9 & 18.00 & GY & 31 & NP & NP & NP & - & 72 & 1 & 27 & ML & & 12 \\
\hline 10 & 18.00 & YG & 37 & 40 & 30 & 10 & 0.78 & 89 & 0 & 11 & MI & & 12 \\
\hline 11 & 18.00 & Y & 27 & 28 & NP & NP & - & 78 & 0 & 22 & ML & & 15 \\
\hline 1 & 19.50 & YG & 32 & 35 & NP & NP & - & 89 & 0 & 11 & ML & & 20 \\
\hline 2 & 19.50 & YG & 24 & 24 & NP & NP & - & 53 & 1 & 46 & ML & & 16 \\
\hline 3 & 19.50 & YG & 22 & NP & NP & NP & - & 65 & 0 & 35 & ML & & 14 \\
\hline 4 & 19.50 & YG & 28 & NP & NP & NP & - & 47 & 1 & 52 & SM & & 10 \\
\hline 5 & 19.50 & GY & 27 & NP & NP & NP & - & 57 & 0 & 43 & ML & & 11 \\
\hline 6 & 19.50 & $\mathrm{Y}$ & 31 & NP & NP & NP & - & 44 & 0 & 56 & SM & & 13 \\
\hline 7 & 19.50 & YG & 28 & NP & NP & NP & - & 47 & 1 & 52 & SM & & 13 \\
\hline 8 & 19.50 & YG & 31 & NP & NP & NP & - & 67 & 0 & 33 & ML & 8 & 15 \\
\hline 9 & 19.50 & GY & 24 & NP & NP & NP & - & 64 & 0 & 36 & ML & & 13 \\
\hline 10 & 19.50 & $\mathrm{Y}$ & 24 & NP & NP & NP & - & 49 & 0 & 51 & SM & & 10 \\
\hline 11 & 19.50 & $\mathrm{Y}$ & 24 & NP & NP & NP & - & 59 & 0 & 41 & ML & & 31 \\
\hline
\end{tabular}

a: açık, K: Kahve, Y: Yeşil, G: Gri

\section{ANALIZZLER}

\subsection{Taşıma Gücü ve Konsolidasyon}

Yapılaşma alanının hemen sınırında bulunan fabrika yapısı için 2012 yılında gerçekleştirilmiş zemin etüt çalışmasında yapılan 9 adet sondajdan $2.50 \mathrm{~m}$ derinlikte dört adet örselenmemiş (UD) numune gelmiştir. Bu numuneler üzerinde yapılan cep penetrometresi okumaları ortalaması 190 kPa'dır. $\mathrm{Bu}$ değerden drenajsız kayma direncinin $\mathrm{c}_{\mathrm{u}}=95 \mathrm{kPa}$ civarında olacağ 1 anlaşılmaktadır. Bununla birlikte laboratuvara gelen bu örselenmemiş kil numuneler üzerinde konsolidasyonsuz drenajsız üç eksenli hücre kesme deneyleri (UU) yapılmış ve $c_{\text {uort }}=50 \mathrm{kPa}$ gibi penetrometre okumasına göre daha düşük bir değer elde edilmiştir. Ayrıca yürütülen bu son çalışma kapsamında açılan hendekten 1.60 metre seviyesinden örselenmemiş numune alınmış ve laboratuvarda konsolidasyonsuz drenajsız üç eksenli hücre kesme deneyine (UU) tabi tutulmuştur. $\mathrm{Bu}$ numunenin $\mathrm{c}_{\text {uort }}=30 \mathrm{kPa}$ gibi düşük bir değer vermesi düşündürücüdür. $\mathrm{Bu}$ nedenle bu düşük deney sonucu kullanılarak yüzeyden 1.00 metre derine oturtulacak, 3.00 metre genişliğindeki 
$\left(D_{f} / B=0.33\right)$ temel için hesaplanan güvenli gerilme de Skempton ile (Şekil 4)

$\sigma_{e m}=\frac{c \times N_{c}}{G S}=\frac{30 \times 5.5}{3}=55 \mathrm{kPa}$

olarak bulunmaktadır [1]. Bu değerin yapılması düşünülen sanayi yapısı için düşük olduğu düşünülmektedir.

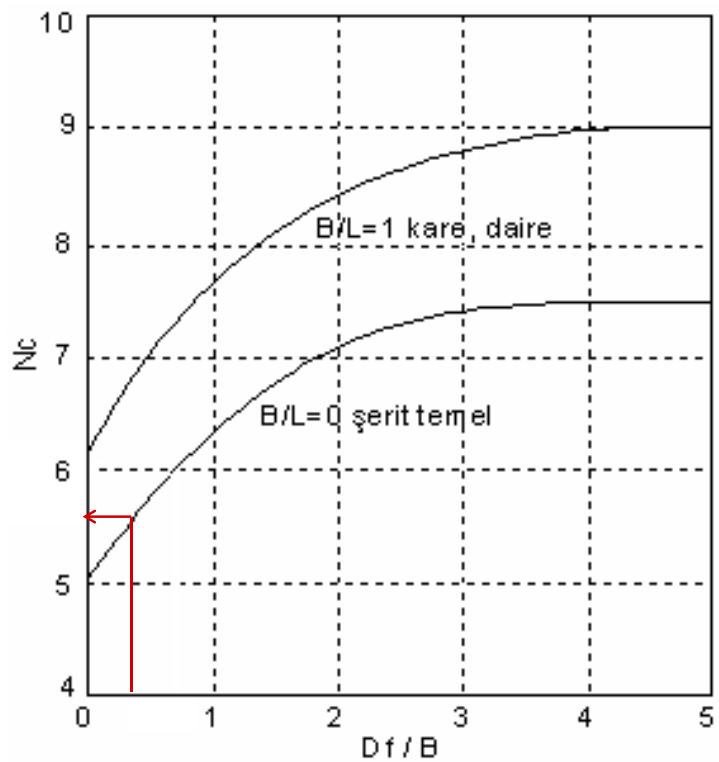

Şekil 4. Kilde oturan temeller için taşıma gücü katsayıs1 [1]

Buradan hareketle, temeller altında yüzeyden $1 \mathrm{~m}$ aşağıdan başlamak üzere $60 \mathrm{~cm}$ çapında, $10 \mathrm{~m}$ boyunda kazıkların kullanılması durumu irdelenmiştir. Buna göre kazık ağırlığı ihmal edilirse ve uç direnci için 2.5 , çevre yapışması için 2 güvenlik sayıları kullanılarak kazıkta $Q_{\mathrm{em}}=970$ $\mathrm{kN}$, kazık ağırlığ ihmal edilirse ve uç direnci için 3 , çevre yapışması için 2.5 güvenlik sayıları kullanılarak kazıkta güvenli taşıma kapasitesi $\mathrm{Q}_{\mathrm{em}}=797.2 \mathrm{kN}$ olarak hesaplanmaktadır. Bilindiği gibi hiçbir temel tipinde temel altında tek kazık kullanımı önerilmemektedir. Temel tipine bağlı olarak gerekli kazık sayısı grup verimi de dikkate alınarak belirlenebilecektir.

$\mathrm{Bu}$ profilde temel altında kalacak sıkışabilir tabaka kalınlığı $6 \mathrm{~m}$ civarında olacaktır. Bununla birlikte yapı içinde maksimum $70 \mathrm{kPa}$ ortalama gerilmeye sahip makinaların montajı söz konusudur. Bu temel basıncı altında sıkışabilir zemin tabakasının orta noktasına aktarılacak ek gerilme $40 \mathrm{kPa}$ olarak alınabilir. Söz konusu seviyede efektif gerilme yaklaşık 43 kPa'dır. Açılan hendekten 1.60 m'den alınan numune üzerinde laboratuvarda konsolidasyon deneyi yapılmış ve en kötü şartlarda zeminin normal yüklenmiş olduğu kabulü ile sıkışma indisinin 0.343 olduğu belirlenmiştir. Buna göre son oturma:

$S_{\infty}=H_{0} \frac{C_{c}}{1+e_{0}} \log \frac{\bar{\sigma}_{0}+\Delta \sigma}{\bar{\sigma}_{0}}=28 \mathrm{~cm}$

gibi yüksek bir değerde tahmin edilmektedir. Buna karşın zeminin hafif derecede aşırı konsolide $(\mathrm{OCR} \approx 2)$ kabul edilmesi durumunda hesaplanacak oturmalar biraz daha aşağılara çekilecektir. Yap1 içinde ayrı temel sistemleri üzerine oturtulabilecek söz konusu makinalar oldukça hassas olduğundan düşeyde herhangi bir deformasyonun oluşması istenmemektedir. $\mathrm{Bu}$ projede temel sisteminin yüzeydeki yumuşak killer üzerinde oturacak olması nedeniyle, meydana gelebilecek oturmaların deplasmana duyarlı hassas makinalar için risk teşkil edeceği açıktır.

$\mathrm{Bu}$ durumda temellerin söz konusu yükler altında taşıma gücü ve konsolidasyon oturması bakımından boyutlandırılması gerekmektedir. Üst metrelerde bulunan sıkışabilir kil tabakaları nedeni ile hem oturma limitlerinin sağlanması hem de taşıma gücünün istenen düzeye yükselmesi amacı ile şerit temel altında yukarıda açıklanan şekilde kazıkların kullanılması önerilmektedir.

\subsection{Sıvılaşma Analizi}

Çalışma alanında bulunan zemin türlerine bakıldığ zaman ortamda sıvılaşabilir düşük plastisiteli siltlerin ve siltli ince kumların varlığı göze çarpmaktadır. Bu tip zeminlerden öncelikle ML sınıfinda olanların sıvılaşma analizleri ince daneli zeminler için geliştirilmiş olan Adapazarı kriterine göre yapılabilmektedir [2]. Adapazarı kriterine göre YASS altındaki doygun siltlerde $M_{w}>7$ olması durumunda sıvılaşmanın gerçekleşebilmesi için şu koşulların sağlanması gerekmektedir: a) Likit limit $\% 33$ 'ten az olmalı, b) Siv1lik indisi $\left(\mathrm{I}_{\mathrm{L}}\right)$ veya $\mathrm{w}_{\mathrm{n}} / \mathrm{w}_{\mathrm{L}}$ 0.9 'dan büyük olmalı, c) Kil oranı \%10'dan az olmalı, d) Ortalama dane boyutu $0.02 \mathrm{~mm}$ 'den büyük olmalı. Bu kriterlere göre çalışma alanındaki siltler detaylı incelendiğinde bazı sondajların değişik seviyelerinde Adapazarı kriterini sağladıkları yani sıvılaşma potansiyeli taşıdıkları görülmektedir. SK-7 ve 8'de 6 metrelerde sıvılaşma potansiyeline sahip bu düşük plastisiteli siltler bulunmaktadir.

Ayrıca tüm sondajlarda 7.50 metreden 10.00 metreye kadar SPTN değerleri 18'e kadar düşebilen siltli kum (SM) tabakaları bulunmaktadır. Temiz kumlar ve siltli kumlar için çevrimsel kayma gerilmesi yöntemine göre hem SPT hem de CPT verisi kullanılarak sıvılaşma analizi yap1labilmektedir [3]. Seed ve Idriss (1971) deprem 
yüklemeleri sırasında oluşan çevrimsel sıvılaşma potansiyelinin belirlenmesi için genel kabul gören bir yöntem geliştirmişlerdir [4]. Bu yöntemde; bir tasarım depremi tarafindan oluşturulan çevrimsel kayma gerilmesi profilinin "cyclic stress ratio" (CSR) ve zeminin çevrimsel direnç oranının "cyclic resistance ratio" (CRR) tahmin edilmesi gerekmektedir. Eğer CSR, CRR'dan büyük ise çevrimsel sıvılaşma meydana gelebilir. CSR'ın tahmini için

$C S R=\frac{\tau_{a v}}{\sigma_{v o}^{\prime}}=0.65\left[\frac{a_{\max }}{g}\right]\left(\frac{\sigma_{v o}}{\sigma_{v o}^{\prime}}\right) r_{d}$

denklemi kullanılmaktadır. Burada $\tau_{\mathrm{av}}$ ortalama çevrimsel kayma gerilmesi; $a_{\max }$ zemin yüzeyinde maksimum yatay ivme; $\mathrm{g}=9.81 \mathrm{~m} / \mathrm{s}^{2}$ yerçekimi ivmesi; $\sigma_{\text {vo }}$ ve $\sigma_{\text {vo }}^{1}$ toplam ve efektif düşey örtü yükü ve $r_{d}$ derinliğe bağlı gerilme azaltma faktörüdür. $r_{d}$

eğer $z<9.15 m \Rightarrow r_{d}=1.0-0.00765 z$

eğer $z=9.15-23 m \Rightarrow r_{d}=1.174-0.0267 z$

basit bağıntıları ile elde edilebilir. Seed vd. (1985) standart penetrasyon deneyi (SPT) ile temiz kumlarda CRR'1 tahmin eden bir yöntem geliştirmişlerdir (Şekil 5) [3]. Bu şekildeki sıvılaşma sınır temel eğrisi aşağıdaki denklem ile ifade edilebilir [5]:

$$
C R R_{7.5}=\frac{1}{34-\left(N_{1}\right)_{60}}+\frac{\left(N_{1}\right)_{60}}{135}+\frac{50}{\left[10 \cdot\left(N_{1}\right)_{60}+45\right]^{2}}-\frac{1}{200}
$$

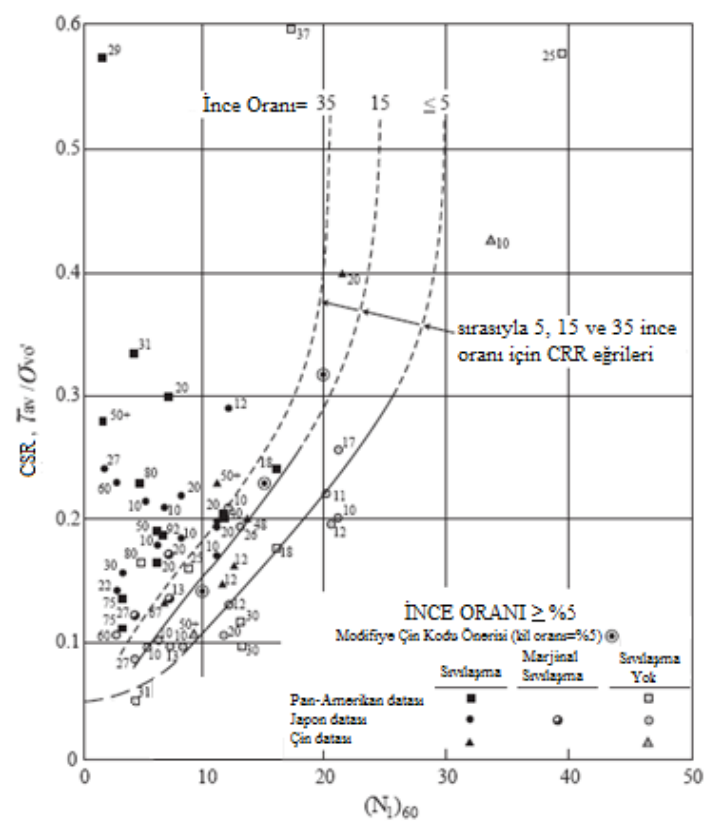

Şekil 5. $\mathrm{M}_{\mathrm{w}}=7.5$ için SPT temiz kum sıvılaşma temel eğrisi [3]
$\mathrm{Bu}$ denklemler $\left(\mathrm{N}_{1}\right)_{60}$ değerinin 30'dan küçük olduğu durumlar için geçerlidir. $\left(\mathrm{N}_{1}\right)_{60}$ değeri 30'dan büyük ise, iri daneli ve temiz zeminlerin sıvılaşmayacak kadar sıkı olduğu kabul edilmektedir. Ayrıca araştırıcılar \%5'ten fazla ince dane içeren iri daneli zeminlerde ince dane düzeltmesinin yapılmasının gerektiğini belirtmektedirler. Buna göre denklemlerde $\left(\mathrm{N}_{1}\right)_{60}$ değeri yerine $\left(\mathrm{N}_{1}\right)_{60 \mathrm{cs}}$ değeri alınmalıdır. Burada;

$$
\left(N_{1}\right)_{60 c s}=\alpha+\beta \cdot\left(N_{1}\right)_{60}
$$

olup $\alpha$ ve $\beta$ katsayıları FC ince dane oranını göstermek üzere aşağıdaki denklemlerden elde edilebilir:

$$
\begin{array}{ll}
\mathrm{FC} \leq \% 5 \text { için } & \alpha=0 \\
\% 5<\mathrm{FC}<\% 35 \text { için } & \alpha=\exp \left[1.76-\left(190 / \mathrm{FC}^{2}\right)\right] \\
\mathrm{FC} \geq \% 35 \text { için } & \alpha=5 \\
\mathrm{FC} \leq \% 5 \text { için } & \beta=1.0 \\
\% 5<\mathrm{FC}<\% 35 \text { için } & \beta=\left[0.99+\mathrm{FC}^{1.5} / 1000\right] \\
\mathrm{FC} \geq \% 35 \text { için } & \beta=1.2
\end{array}
$$

SPT verilerinde ince oranı ve dane karakteristiklerinden başka aşağıdaki denklemde verilen düzeltmeler de yapılmalıdır:

$$
\left(N_{1}\right)_{60}=N_{m} C_{N} C_{E} C_{B} C_{R} C_{S}
$$

Burada $\mathrm{N}_{\mathrm{m}}$ : ölçülen standart penetrasyon direncini; $\mathrm{C}_{\mathrm{N}}$ : efektif örtü basıncı düzeltme katsayısını; $\mathrm{C}_{\mathrm{E}}$ : çekiç enerji oranı düzeltme katsayısını; $\mathrm{C}_{\mathrm{B}}$ : sondaj delik çapı düzeltme katsayısını; $\mathrm{C}_{\mathrm{R}}$ : tij uzunluğu düzeltme katsayısını, $C_{S}$ : numune alıcı düzeltme katsayısını göstermekte olup ilgili değerler literatürden alınabilir. Bundan sonra CRR değeri yüksek örtü basıncı ve statik kayma gerilmesi durumları ve deprem büyüklüğü için düzeltilmelidir [6]:

$$
\begin{aligned}
& C R R_{V}=C R R_{7.5} \cdot K_{\alpha} \cdot K_{\sigma} \\
& M S F=\frac{10^{2.24}}{M^{2.56}}
\end{aligned}
$$

Son yillarda CPT deneyi kesintisiz okuma alabilmesi, güvenilirlik ve tekrar edilebilirliğinin yüksek olmasından dolayı CRR'1 tahmin etmede daha popüler olmuştur. Buna göre tavsiye edilen korelasyon aşağıdaki basitleştirilmiş denklemlerle tahmin edilebilir [7] [8]. 
$50<\left(\mathrm{q}_{\mathrm{clN}}\right)_{\mathrm{cs}} \leq 160$ için $C R R_{7.5}=93\left[\frac{\left(q_{c 1 N}\right)_{c s}}{1000}\right]^{3}+0.08$

$\left(\mathrm{q}_{\mathrm{cIN}}\right)_{\mathrm{cs}}<50$ için $\quad C R R_{7.5}=0.833\left[\frac{\left(q_{c 1 N}\right)_{c s}}{1000}\right]+0.05$

Sonuçta sıvılaşmaya karşı direnç şu şekilde verilir;

$$
F S=\frac{C R R_{7.5}}{C S R} M S F
$$

$\mathrm{Bu}$ çalışma kapsamında sondajlardan gelen veriler ile yapılan sıvılaşma analizleri bahsi geçen siltli ve kumlu seviyelerin sıvılaşma potansiyeli taşıdığını göstermektedir (Tablo 2).

Tablo 2. Çevrimsel kayma gerilmesi yöntemine göre SPT verileri sıvılaşma analiz sonuçları

\begin{tabular}{cccccccccccc}
\hline z $(\mathrm{m})$ & SK-1 & SK-2 & SK-3 & SK-4 & SK-5 & SK-6 & SK-7 & SK-8 & SK-9 & SK-10 & SK-11 \\
\hline 1.5 & Yok & Yok & Yok & Yok & Yok & Yok & Yok & Yok & Yok & Yok & Yok \\
3 & Yok & Yok & Yok & Yok & Yok & Yok & Yok & Yok & Yok & Yok & Yok \\
4.5 & Yok & Yok & Yok & Yok & Yok & Yok & Yok & Yok & Yok & Yok & Yok \\
6 & Yok & Yok & Yok & Yok & Yok & Yok & Var & Var & Yok & Var & Yok \\
7.5 & Var & Var & Var & Var & Var & Var & Var & Var & Var & Var & Yok \\
9 & Yok & Yok & Yok & Yok & Var & Yok & Var & Var & Var & Yok & Yok \\
12 & Var & Yok & Yok & Yok & Yok & Var & Yok & Yok & Yok & Yok & Var \\
15 & Yok & Var & Yok & Var & Yok & Yok & Yok & Var & Yok & Yok & Yok \\
\hline
\end{tabular}

SPT veya CPT verileri ile yapılan çevrimsel kayma gerilmesi yöntemi analizine ek olarak Iwasaki vd. (1978) tarafından geliştirilen sıvılaşma potansiyeli indisi (LPI) yöntemi ile de analiz yapılmıştır [9]. $\mathrm{Bu}$ araştırıcılara göre sıvılaşmanın büyüklüğ̈̈; sıvılaşan tabaka kalınlığı, sıvılaşır tabakanın yüzeye olan yakınlığı ve güvenlik katsayısının (FS) 1'den küçük olduğu miktar ile orantılıdır. Burada FS sıvılaşmaya karşı direncin deprem tarafından beliren yüke oranını göstermektedir. Araştırmacılar, 20 m'den daha büyük derinliklerde sıvılaşmanın yüzeye etkisinin çok nadir belireceği gerekçesiyle LPI'nın hesabını 0 ila $20 \mathrm{~m}$ arasında sınırlandırmışlar ve aşağıda verilen tanımlamayı önermişlerdir.

$$
L P I=\int_{0}^{20 m} F w(z) d z
$$

Burada $\mathrm{z}$ metre boyutunda derinlik, $\mathrm{w}$ ise derinlik ağırlık faktörü olmak üzere;

$\mathrm{FS} \leq 1$ için $\mathrm{F}=1-\mathrm{FS}$

$\mathrm{FS}>1$ için $\mathrm{F}=0$

$\mathrm{w}(\mathrm{z})=10-0.5 \mathrm{z}^{\prime} \mathrm{dir}$.

Buna göre; LPI'nın 5'ten küçük olması sıvılaşma potansiyelinin olmadığını veya düşük olduğunu, 515 arasında olması orta, 15 'ten büyük olması durumu ise yüksek sıvılaşma potansiyelini göstermektedir. Toprak ve Holzer (2003) 1989 Loma Prieta, California depremindeki sıvılaşmanın yüzey gözlemleri ile LPI korelasyonunu incelemişler ve sıvılaşma olayının tipik olarak LPI değerinin 5 değerini aştı̆̆ 1 durumlarda gerçekleştiğini belirlemişlerdir [10].

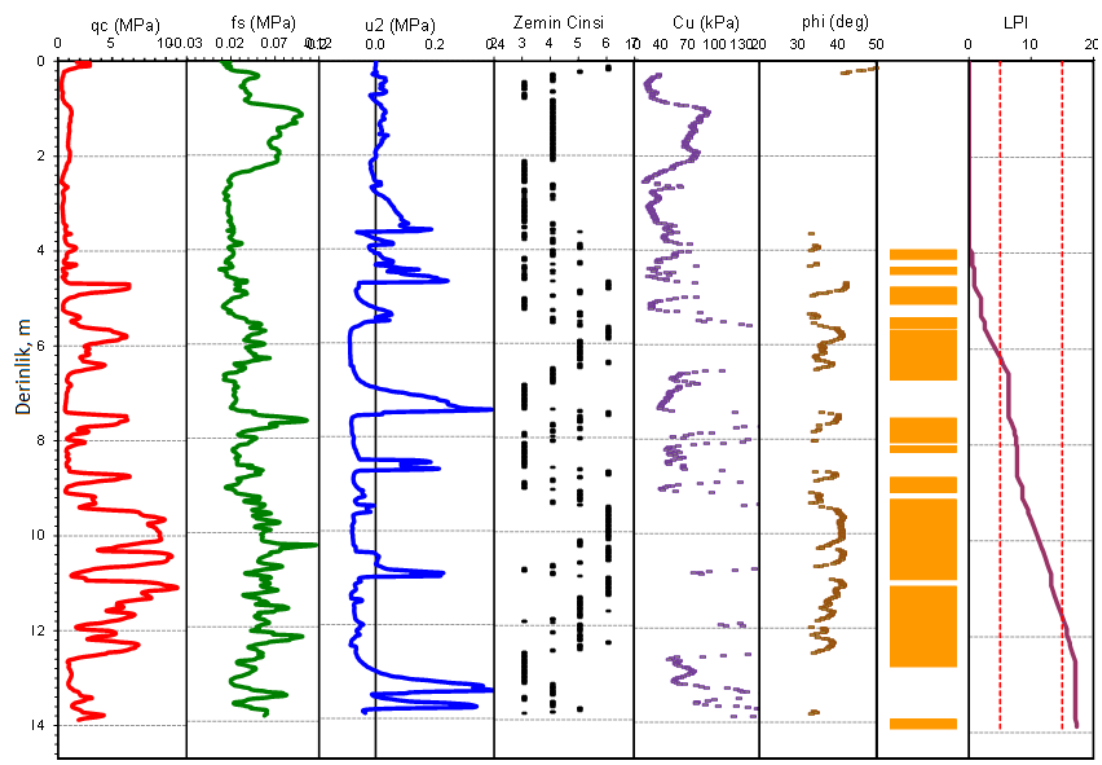

Şekil 6. 2001 yılında fabrika arazisinde yapılmış koni penetrasyon deneyi sıvılaşma analizi 
Fabrika arazisinde 1999 depreminden sonra 2001 yılında Sakarya Üniversitesi Geoteknik Çalışma Grubu tarafından gerçekleştirilen beş adet PCPT deneyinden biri olan CPT-2 sondası verileri bu çalışma kapsamında sıvılaşma açısından irdelenmiştir. Şekil 6'da verilen LPI sıvılaşma analizi sonuç grafiğinden güvenlik sayısının yer yer birin altında çıktığı anlaşılmakta olup şekilde turuncu renkler sıvılaşabilir zeminleri göstermektedir. CPT-2 sondasında 14 metre derinlik için LPI 16.30 olarak belirlenmiş ve parselin yüksek sıvılaşma potansiyeline sahip olduğu teyit edilmiştir. Kısaca taşıma gücü ve konsolidasyon oturmalarını kontrol altına almanın yanında; sıvılaşma açısından da alanda temel altından itibaren sık1 kumlara kadar zemin iyileştirmesi gerektiği ortaya çıkmıştır.

\section{ARAŞTIRMA SAHASINDA MORFOLOJIK DÜZENSIZLLIK \\ BULUNAN}

1999 depreminden sonra arazi gözlemleri sırasında alüvyonda Erenler tepesinin kuzey kenarına yaklaşık $500 \mathrm{~m}$ uzakta morfolojik bir değişiklik gözlemlenmiştir [11]. Buna göre deprem sirasında arazide, yaklaşık doğu-batı doğrultulu bir çökme meydana gelmiş olup hattın kuzey tarafı güneye göre 10-30 cm arasında değişen mesafelerde düşüktür. Bol (2003) söz konusu hat boyunca görülen yüzey deformasyonlarını detaylı bir şekilde inceleyerek deformasyon hattını haritalamıştır [11] (Şekil 7). İnceleme sırasında, Şekil 7'de 1 ve 2 nolu bölge olarak gösterilen fabrika yapısının batı ve doğu duvarlarının kuzey kısımlarının güney tarafına oranla yaklaşı $20-25 \mathrm{~cm}$ aşağıya çöktüğü gözlemlenmiştir. Fabrika içinde yüzeyde kırıklar gözlemlenmiş ve 1999 depreminin hemen sonrasında fotoğraflanmıştır (Şekil 8-9).

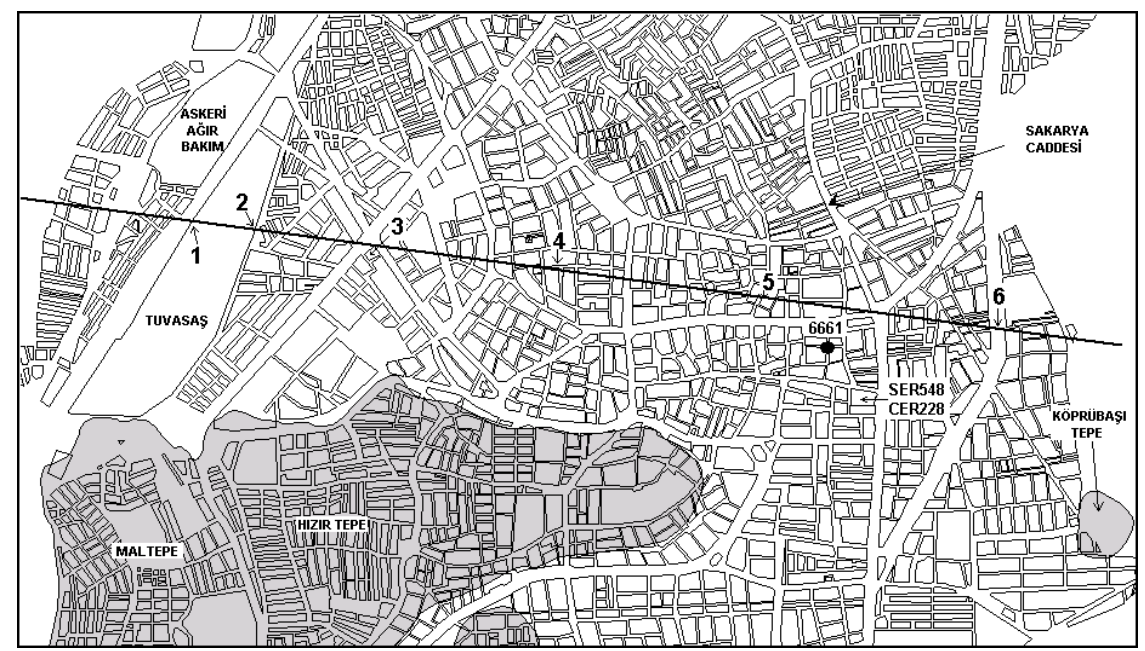

Şekil 7. 1999 depremi sonrası Erenler kuzeyinde görülen morfolojik düzensizlik hattı

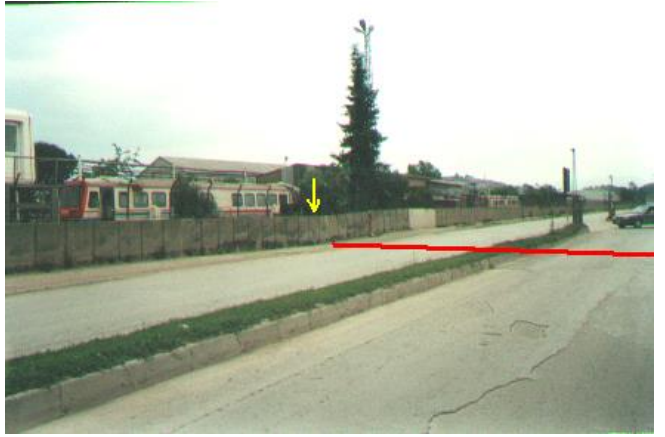

Şekil 8. Şekil 7'de 1 nolu bölge, duvarda çökme

Hattın doğu tarafinda Şekil 7'de 3 nolu gözlem noktası olarak gösterilen Güllük camisi bahçe duvarlarında deprem sonrası kuzey tarafta bir göçme olduğu gözlemlenmiştir. 4 nolu gözlem noktasında Dilmen İlköğretim Okulu bulunmakta olup, okulun bahçesinde batıdan çekilmiş

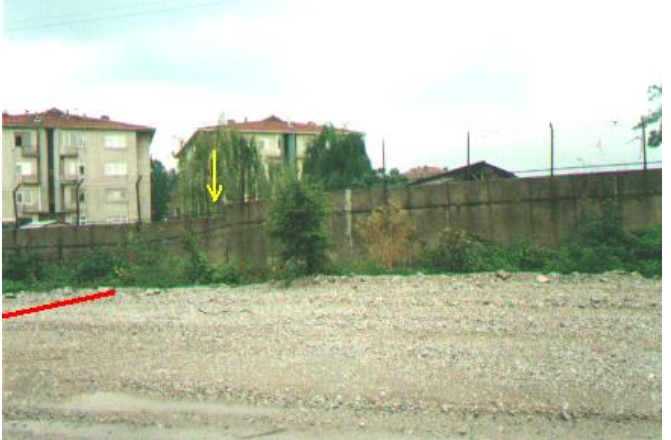

Şekil 9. Şekil 7'de 2 nolu bölge, duvarda çökme

fotoğrafta, yüzeyde belli bir hat boyunca çökme meydana gelmiş olduğu ve kuzey tarafın güneye göre daha aşağıda olduğu görülmektedir (Şekil 10). Fotoğrafta gösterilen hattın oluşumunda görgü tanıkları çökmenin ardından fark edilir bir sarsıntı yaşanmadığını ve ilerleyen günlerde çökme 
miktarının zamanla arttığını ifade etmişlerdir [11]. $\mathrm{Bu}$ çökmenin oluşumundan sonra sarsıntı olmaması ve çökmenin bir süre daha devam etmesi göz önüne alınırsa burada harekete geçen aktif bir fayın bulunmadığı söylenebilir.

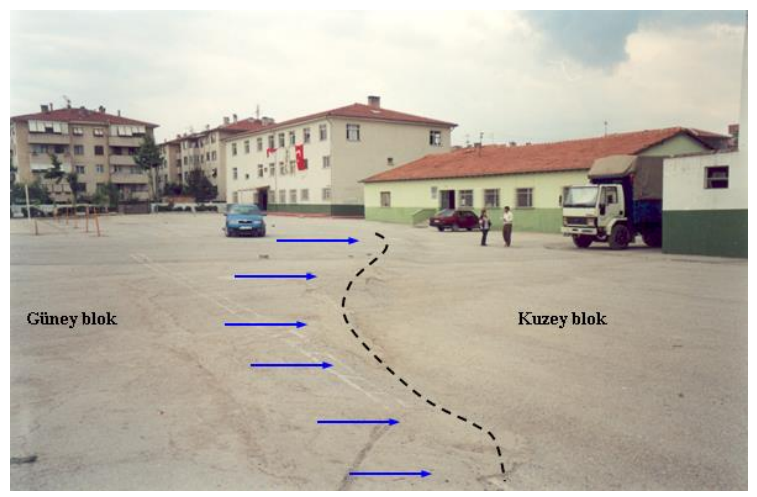

Şekil 10. Şekil 7'de 4 nolu gözlem noktasında bulunan okulda alçalan kuzey bloğu

5 nolu gözlem noktasında birkaç evin bahçe duvarlarının kuzey kısımlarının güneye göre daha aşağıda olduğu tespit edilmiştir. Bunların dışında 6 nolu gözlem noktasında Elmas Otel civarında Sakarya Caddesinde çökme olduğu gözlemlenmiş, civarda yaşayanlar deprem sonrası buradaki çökmelerin yaklaşı $50 \quad \mathrm{~cm}$ olduğunu belirtmişlerdir. Erken vd. (2001-2003) yürüttükleri araştırma projesi kapsamında morfolojik düzensizlik hattı üzerinde arazi gözlemleri ve belli bölgelerde sismik ölçümler yapmışlardır [12]. Buna göre bu hattın altında gömülü bir fay olduğunu ve 17 Ağustos 1999 depreminde bu fayın harekete geçtiğini belirtmişlerdir. Ancak özellikle bir artçı deprem belirlenmemiş olması bu görüşün kuşku ile karşılanmasına neden olmaktadır. Bu morfolojik düzensizlik Şekil 11'e göre Bol (2003) tarafindan şu şekilde yorumlanmıştır [11]:

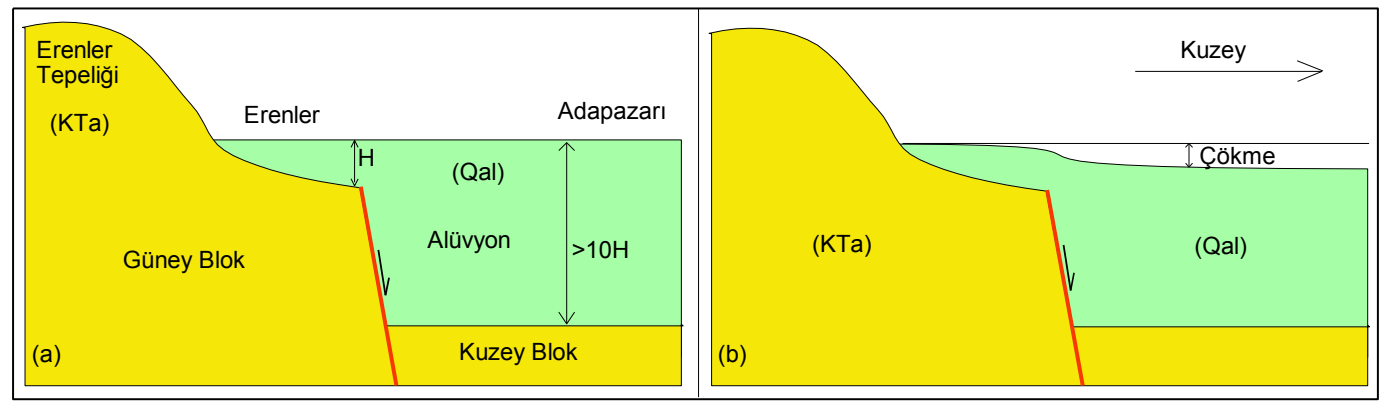

Şekil 11. 1999 depremi sonrası Erenler'de meydana gelen morfolojik düzensizliğin oluşum mekanizması a) deprem öncesi, b) deprem sonrası

1. Şekil 11'de morfolojik düzensizlik hattını içine alacak şekilde kuzey-güney yönlü ölçeksiz bir kesit verilmiştir. Burada alüvyon altında söz konusu hat boyunca önceden oluşmuş doğu batı doğrultulu ve kuzey bloku güneye göre aşağıda olan ve diri olmayan gömülü bir normal fay vardır (Şekil 11a). Dolayısı ile kuzey bloku üzerinde bulunan alüvyon tabakasının kalınlığı güney bloğunun üzerinde bulunan alüvyon tabakasının kalınlığına oranla çok daha fazladir.

2. Deprem sonrasında alüvyon altında bulunan eski fayın harekete geçmemesine karşın kuzeyde bulunan alüvyon tabakası, güney bloğun üzerinde bulunan alüvyona göre daha fazla çökmüş ya da sıkışmış (Şekil 11b) ve depremin 45 saniye gibi uzun bir süre sarsıntı yaratması bu çökmeyi belirginleştirmiștir. Sonuç olarak yüzeyde bu fayın izdüşümü olan hat boyunca morfolojik bir farklılık oluşmuştur.

\subsection{Sahada Yapılan Hendek Çalışması}

Yukarıda 1999 depreminde ortaya çıkan ve söz konusu fabrika arsasının kuzey tarafından geçen yaklaşık doğu-batı doğrultulu çöküntü bölgesinin kesin yerini belirlemek için hendek (trench) araştırması yapılması düşünülmüştür. Bu amaçla 14 Nisan 2016 tarihinde araziye gidilmiş ve çöküntünün olduğu bölgeyi kesen bir hendek kazılmıştır. Hendek yaklaşık 1.50 metre genişliğinde ve ortalama 2 metre derinliğinde olup kazı 24 metre boyunca sürdürülmüştür (Şekil 12a). Kazı hattı Şekil 13'de, başlangıç-bitiş koordinatları 
ise Şekil 14'de sunulmaktadır. Kazı sırasında hat boyunca yaklaşık 1.60-1.80 metre derinliklerde kahverengi killerden aniden yeşil renkli killere geçiş gözlemlenmiştir. Bununla birlikte iki tabaka sınırı arasından gelen yoğun su miktarı sebebi ile hendek derinleştirilse de dolan su nedeni ile gözlem yapma imkânı bulunamamıştır. $\mathrm{Bu}$ nedenle çöküntünün saptanabileceği sınır olarak sadece söz konusu kahve ve yeşil renkli tabaka sınırındaki farklılıklar incelenmiştir. Yapılan ölçümlerde hendeğin kuzey tarafindaki tabaka sınırının en güney uçta yapılan ölçüme göre yaklaşık $40 \mathrm{~cm}$ civarında daha derinde olduğu saptanmıştır. Değişimin hangi noktada kesin olarak başladığını belirlemek için güney kanadında birkaç tali küçük hendek açılmış ve söz konusu tabaka sınırı bu hendeklerde $160 \mathrm{~cm}$ olarak ölçülmüştür (Şekil 12b). $\mathrm{Bu}$ sınırın daha kuzey seviyelerinde yeşil tabaka sınırı 180-200 cm civarında ölçülmektedir (Şekil 14).

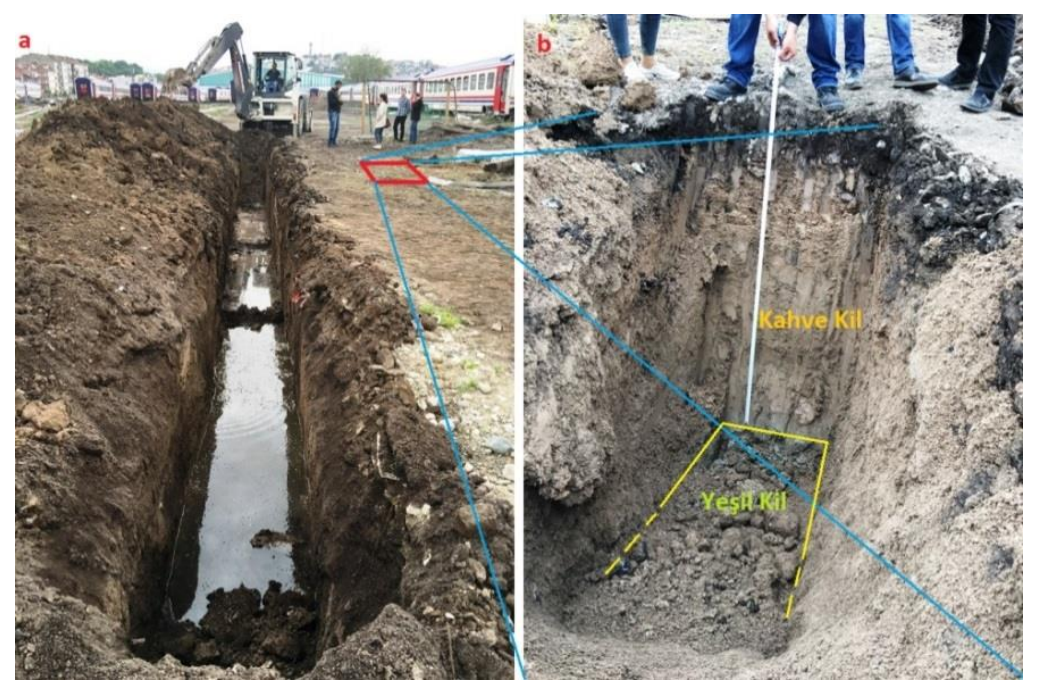

Şekil 12. Çalışma alanında çöküntü sınırını belirlemek için açılmış hendek

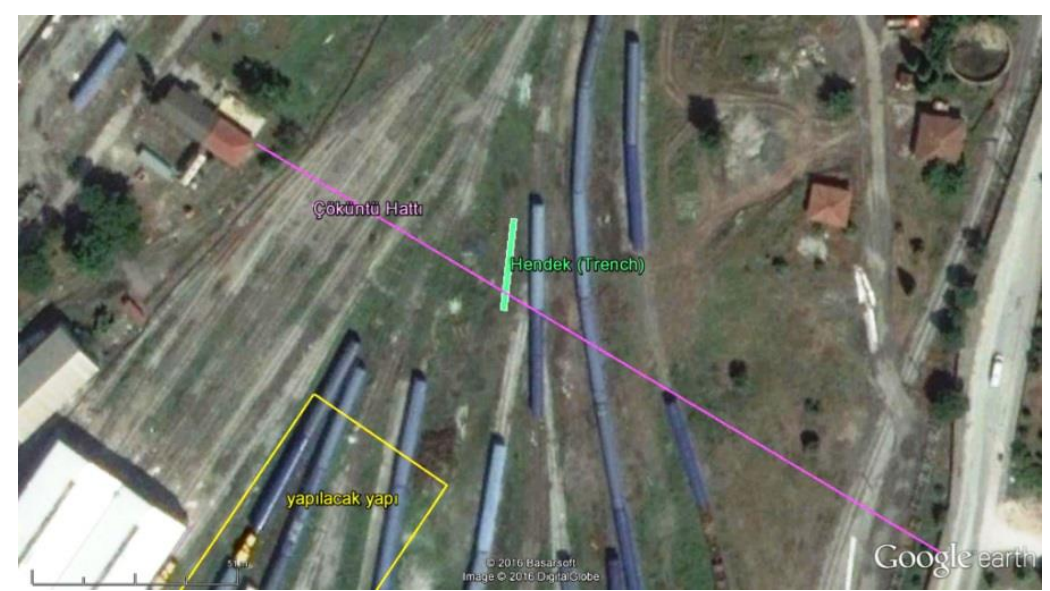

Şekil 13. Arazide açılan hendeğin ve yeni yapılaşma sınırının uydu fotoğrafı üzerindeki konumu

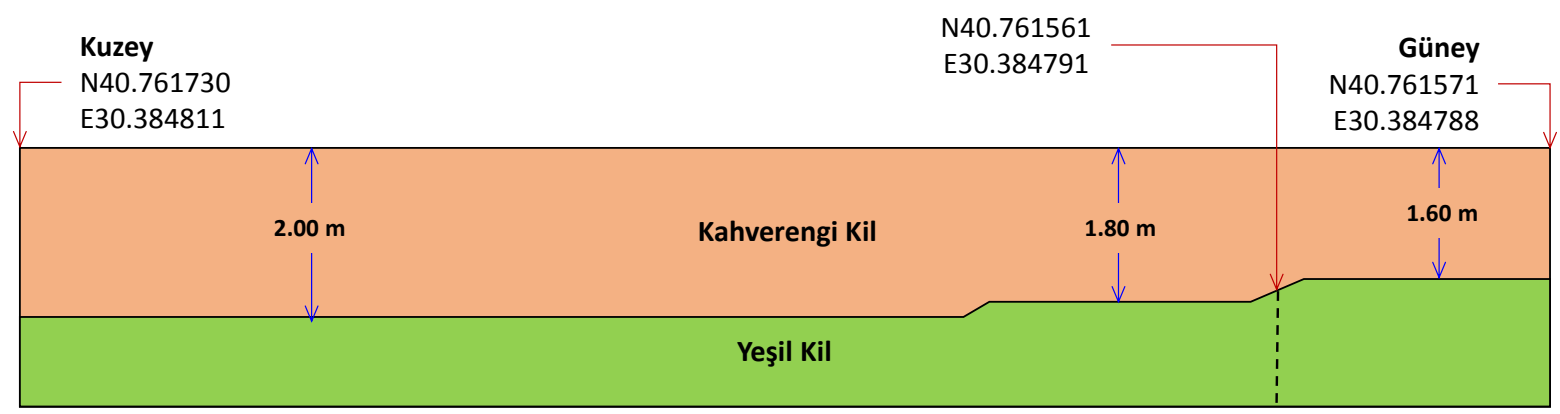

Şekil 14. Hendek kesiti 
Şekil 13, arazide açılan hendeğin uydu fotoğrafi üzerindeki konumu ile yeni yapılacak yapıya göre olan konumunu da göstermektedir. Arazide 1999 depremi sonrası meydana gelen çöküntünün fabrika alanı sınırlarını çevreleyen duvarları üzerindeki deformasyonları Şekil 8 ve 9'da sunulmuştu. Bu çalışma kapsamında da elde edilen deformasyon hattı duvarlardaki çöküntü noktaları ile birleştirildiğinde Şekil 13'de çöküntü hattı olarak nitelendirilen çizgi elde edilmektedir. Bazı araştırıcılara göre gömülü bir fayın yeryüzündeki iz düşümü olarak nitelendirilen bu hat üzerinde yapılaşma risk arz etmektedir. Ülkemizde diri fayların civarında yapılaşma şartlarını düzenleyen bir yönetmelik olmamasına karşın literatürde bu konuda yapılmış çalışmalar bulunmaktadır. Geniş kabul gören çalışmaların başında gelen McCalpin (1987)'e göre fay sarplığının \%30'dan küçük olduğu durumlarda (Şekil 15a) bu sarplığın orta noktasından itibaren iki yana doğru 15 'er metre genişliğindeki alanda yapılaşma yasağının getirilmesi gerekmektedir [13]. Fay sarplığının \%30'dan büyük olduğu durumda ise (Şekil 15b) 15 m'lik mesafe fay yamacından sonra ölçülmektedir.
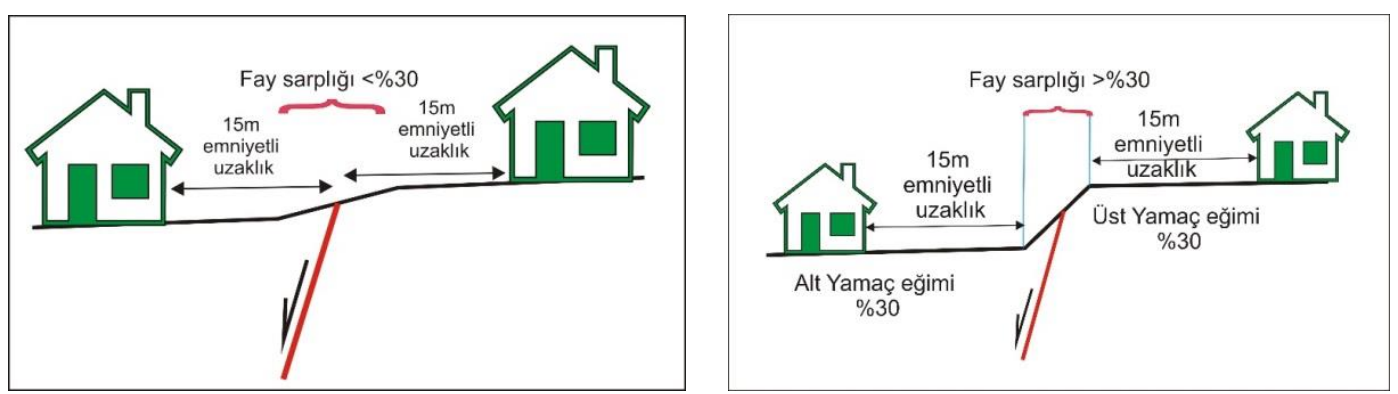

Şekil 15. Tampon bölge a) Yamaç eğimi \%30’dan düşük b) Yamaç eğimi \%30’dan fazla

Söz konusu çalıșma alanında yapılması planlanan yapı konut tipi olmadığından ve üzerine ağır tonajlı hassas robot kolların yerleştirilmesi düşünüldüğ̈̈nden fay hattından uzaklık konusunda yukarıda verilen sınır değerlerin iki katının alınmasının uygun olacağı düşünülmektedir. Buna göre söz konusu çöküntü hattının her iki tarafindan 30'ar metrelik mesafelere yapılaşma yapılmaması uygun olacaktır.

\section{SONUÇLAR}

$\mathrm{Bu}$ çalışmada, problemli zeminler üzerinde inşası planlanan fabrika yapısı için yapılan incelemeler ortaya konmaktadır. Parsel zeminlerinin üst kısımları taşıma gücü ve oturma açısından problemlidir ve aynı zamanda sıvılaşma potansiyeline sahip silt ve kum tabakalarını içerdiğinden sağlam katmanların bulunduğu en az 11 metreye kadar iyileştirme yapılması gerekmektedir. İyileştirme yöntemi olarak jet-grout ile oluşturulacak yüksek modüllü kolonlar düşünülebileceği gibi temel yüklerinin sağlam zemine aktarılabileceği kazıklı temel sistemleri de düşünülebilir. Makine ve yapı temelleri için; üst metrelerde bulunan sıkışabilir kil tabakaları nedeni ile hem oturma limitlerinin sağlanması hem de taşıma gücünün istenen düzeye yükselmesi amacı ile şerit temel altında kazıkların kullanılması önerilmektedir. Bu zemin ortamında $60 \mathrm{~cm}$ çaplı, yüzeyden 1 metre aşağıdan başlamak şartı ile $10 \mathrm{~m}$ boyunda tek bir kazığın kapasitesi 2240 kN'dur. Tek bir kazık için güveli yük güvenlik sayısına bağlı olarak 800-970 kN arasında alınabilir. Temel altlarında kaç metre aralıklarla yerleştirileceği temel boyutlarının ve temel yükünün net olarak belirlenmesi ile grup verimi de göz önüne alınarak yapılabilir. Ayrıca, parselde 1999 depremi sonrasında fark edilen bir morfolojik bozukluk mevcuttur. Bu bozukluk 1999 depreminde hat boyunca arazinin 25-50 cm aşağı çökmesiyle kendini göstermiştir. İnşaat yapılacak söz konusu alan bu hatta en az 40 metre mesafede olduğundan söz konusu inşaat için riskli bir durum teşkil etmemektedir.

\section{KAYNAKLAR}

[1] A. Önalp ve S. Sert, Geoteknik Bilgisi III Bina Temelleri, Güncelleştirilmiş 3. Baskı, İstanbul: Birsen Yayınevi, 2016.

[2] E. Bol, A. Önalp, E. Arel, S. Sert and A. Özocak, Liquefaction of silts: the Adapazar1 Criteria, Bulletin of Earthquake Engineering, vol. 8, no. 4, pp. 859-873, 2010.

[3] H. Seed, K. Tokimatsu, L. Harder and R. Chung, Influence of SPT procedures in soil liquefaction resistance evaluations, Journal of Geotechnical Engineering, ASCE, vol. 111, no. 12, pp. 1425-1440, 1985.

[4] H. Seed and I. Idriss, Simplified procedure for evaluating soil liquefaction potential, ASCE Journal of Geotechnical Engineering, vol. 97, no. 9, pp. 1249-1273, 1971. 
Geliş Tarihi/Received Date: 2017-06-08 Kabul Tarihi/Accepted Date: 2017-09-06

[5] T. Youd and I. Idriss, Liquefaction resistance of soils: summary report from the 1996 NCEER and 1998 NCEER/NSF workshop on evaluation of liquefaction resistance of soils, ASCE Journal of Geotechnical Engineering, vol. 127, no. 4, pp. 297-313, 2001.

[6] H. Seed, Earthquake-resistant design of earth dams, Proc. Symp. Seismic Des. of Earth Dams and Caverns, ASCE, pp. 41-64, New York, 1983.

[7] P. Robertson and C. Wride, Evaluating cyclic liquefaction potential using the cone penetration test, Canadian Geotechnical Journal, vol. 35, no. 3, pp. 442-459, 1998.

[8] P. Robertson, Evaluating soil liquefaction and post-earthquake deformations using the CPT, University of Alberta, Department of Civil and Environmental Engineering, Edmonton, Canada, 2004.

[9] T. Iwasaki, F. Tatsuoka, K.-i. Tokia and S. Yasuda, A practical method for assessing soil liquefaction potential based on case studies at various sites in Japan, Proc. 2nd International Conference on Microzonation, pp. 885-896, San Francisco, 1978.
[10] S. Toprak and T. Holzer, Liquefaction potential index: field assessment, J. of Geotechnical and Geoenvironmental Engineering, ASCE, vol. 129, no. 4, pp. 315-322, 2003.

[11] E. Bol, Adapazarl Zeminlerinin Geoteknik Özellikleri, Doktora Tezi, Adapazarı: Sakarya Üniversitesi, 2003.

[12] A. Erken vd., 7 Ağustos Kocaeli Depreminde Adapazarında Oluşan Hasar Üzerinde Yerel Zemin Koşullarının Etkisi, Türk Deprem Vakfı Araştırma Projesi, Proje No: 00-AP-113, 2001 2003.

[13] J. McCalpin, Recommended setback distances from active normal faults, Proceedings of the Symposium on Engineering Geology and Soils Engineering, 1987. 